\title{
Assessment of maternal health services utilization in Pakistan: the role of socio-demographic characteristics
}

\author{
Muhammad Aslam', Maryam Sadiq2,*, Tahir Mehmood ${ }^{3}$
}

\section{Abstract}

Background: High-quality prenatal care has a significant positive impact on maternal and infant health as it helps timely diagnosis and treatment of pregnancy complications.

Objective: To examine factors associated with the utilization of maternal health care using the optimal count regression model.

Methods: A sample of 16,314 women of reproductive ages (15-49) was used. Andersen and Newman's behavioral model of health services utilization was employed for the selection of covariates. Poisson, negative binomial, zeroinflated Poisson, zero-inflated negative binomial (ZINB), Poisson hurdle, and negative binomial hurdle models were fitted and compared to identify the best model. Maternal health care utilization is found associated with maternal age and education, area of residence, domestic violence, the income level of family, access to media, knowledge about AIDS, parity, birth order, and having a child who later died.

Results: ZINB model is found to be best fitted for the observed data resulting strong influence of mother's education and income level of the family on maternal health care utilization.

Conclusion: Interventions to improve maternal care services utilization should address individuals and systems to reduce social and economic marginalization.

Keywords: count; maternal; Pakistan; Poisson; zero-inflated

Maternal health care must be focused to reduce morbidity and mortality of mothers and newborns. Maternal health is an indicator of safe pregnancy, risk-free childbirth, and a step toward a healthy childhood and prosperous life. There is evidence that pregnancy-related complications cause maternal mortality and disabilities [1]. Large variations of maternal mortality ratios represent the consistent gap in health index between developing and developed countries, specifying the dilapidated condition of maternal health care in some developing countries [2]. The Universal Declaration of Human Rights states that special care and assistance should be privileges for pregnant women [3]. The significance of maternal health care was initially acknowledged in 1987 internationally, and a progressive campaign on safe motherhood is continued

*Correspondence to: Maryam Sadiq, Department of Statistics, University of Azad Jammu and Kashmir, Muzaffarabad 13100, Pakistan, e-mail: maryam.sadiq@uajk.edu.pk

'Department of Mathematics and Statistics, Riphah International University, Islamabad 45210, Pakistan

${ }^{2}$ Department of Statistics, University of Azad Jammu and Kashmir, Muzaffarabad 13100, Pakistan

${ }^{3}$ School of Natural Sciences (SNS), National University of Sciences and Technology (NUST), Islamabad 44000, Pakistan 
by several organizations subsequently [4]. More than $50 \%$ of all maternal deaths occurred in only six countries, worldwide, including Pakistan where the maternal mortality rate is 276 deaths per 100,000 births reflecting the dire condition of maternal health care $[5,6]$. Pakistan is yet a far way to achieve the millennium development goals in maternal health. A reason for this failure is that maternal health care plans have failed to identify the factors that restrict access to pregnancy-related care for women belonging to the social and economic edges of a specific community. Concern has been discussed about the potential determinants of maternal health care utilization across geographical areas. Although research in Pakistan has reported significant socioeconomic factors of maternal health care utilization employing descriptive analyses of covariates, there have been little investigations that could precisely explore the significant causes of this issue using complex statistical methodology [7, 8]. This study examines the predisposing, enabling, and pregnancy-related characteristics of the health behavior model developed by Andersen and Newman using six highly recommended complex count data models for a deeper and precise understanding of maternal health care utilization model.

\section{Methods}

Non-parametric tests including Mann-Withney and KruskalWallis tests are used for the bivariate analysis of the number of maternal care visits. Count regression models including Poisson [9, 10], negative binomial (NB) [11-13], zero-inflated Poisson (ZIP), zero-inflated negative binomial (ZINB), Poisson hurdle $(\mathrm{PH})$, and negative binomial hurdle $(\mathrm{NBH})$ regression model are fitted to identify the significant factors associated with maternal care services utilization. Akaike's information criterion (AIC) is used for assessment and comparison of models.

The data of Pakistan used for this study are obtained from UNICEF's Multiple Indicator Cluster Survey (MICS). This survey was conducted in 2014 with the support of the Bureau of Statistics Punjab, Bureau of Statistics Sindh, Government of the Punjab, and Government of Sindh, Pakistan. MICS is an international program to conduct surveys to collect internationally comparable measures on a wide range of demographic indicators related to women. The secondary dataset of two provinces of Pakistan (Punjab and Sindh) is used for analyses. In this study, women aged 15-49 are included who had pregnancy during the last 2 years before the conduct of the survey. Hence, 16,314 women with complete data of relevant factors are included in the analysis.

\section{Variables}

The outcome factor in this study is the number of maternal health care visits utilized by pregnant women. The zero count of maternal visits shows non-use of maternal services. Maternal services utilization is examined regarding predisposing, enabling, and pregnancy-related features of the health behavior model developed by Andersen and Newman. Province, woman's age, educational level, husband's age, domestic violence, area, and province and are considered as predisposing factors. Income level, experience of a child's death, access to media, and AIDS awareness are characterized as enabling features. Pregnancy-related factors include desire for pregnancy, parity, and birth order.

\section{Results}

\section{Bivariate analysis}

Table 1 represents the descriptive statistics of predisposing, enabling, and pregnancy-related features of the sample. Kruskal-Wallis test shows that maternal care utilization is significantly associated with income level. Mann-Whitney test establishes the significant association of maternal care utilization with the province, woman's age, woman's educational attainment, area, domestic violence, access to media, AIDS awareness, an experience of a child's death, desire for pregnancy, parity, and birth order.

Figure 1 represents that zero counts showing that the non-use of maternal care has the highest proportion than all positive counts. The likelihood ratio test for overdispersion between Poisson and negative binomial distribution shows a $\chi^{2}$ test-statistics $=6113$ with a critical value test statistics $=2.7$ and $P<0.001$ which is strong evidence of overdispersion in the observed data.

\section{Model comparison}

For all count regression models including NB, ZINB, NBH, Poisson, ZIP, and PH, the values of AIC are computed, and the comparison is presented in Figure 2.

The graphical representation of model assessment criteria demonstrates the difference between performance and accuracy of different count models. Figure $\mathbf{2}$ shows that models based on NB distribution have higher efficiency with a low value of AIC. This is the indication of overdispersion 
Table 1. Characteristics of the study sample $(N=16,314)$ and significance of maternal care visits between subgroups

\begin{tabular}{|c|c|c|c|}
\hline $\begin{array}{l}\text { Predisposing } \\
\text { characteristics }\end{array}$ & N (\%) & $\begin{array}{c}\text { Median } \\
\text { (P25-P75) }\end{array}$ & $P$ \\
\hline \multicolumn{4}{|l|}{ Province* } \\
\hline Punjab (Pakistan) & $10,278(63)$ & $3(2-6)$ & $<0.01$ \\
\hline Sindh (Pakistan) & $6,036(37)$ & $2(1-5)$ & \\
\hline \multicolumn{4}{|l|}{ Age $^{*}$} \\
\hline$\leq 20$ years & $1,773(10.9)$ & $3(1-5)$ & $<0.01$ \\
\hline$>20$ years & $14,541(89.1)$ & $3(1-5)$ & \\
\hline \multicolumn{4}{|l|}{ Education level ${ }^{*}$} \\
\hline Illterate & $8,499(52.1)$ & $2(0-4)$ & $<0.01$ \\
\hline Literate & $7,815(47.9)$ & $4(3-7)$ & \\
\hline \multicolumn{4}{|l|}{ Area* } \\
\hline Urban & $5,813(35.6)$ & $4(2-7)$ & $<0.01$ \\
\hline Rural & $10,501(64.4)$ & $2(1-4)$ & \\
\hline \multicolumn{4}{|l|}{ Husband's age* } \\
\hline$\leq 30$ years & $6,760(41.4)$ & $3(1-5)$ & $<0.32$ \\
\hline$>30$ years & $9,554(58.6)$ & $3(1-6)$ & \\
\hline \multicolumn{4}{|c|}{ Domestic violence* } \\
\hline Yes & $8,667(46.9)$ & $2(1-4)$ & $<0.01$ \\
\hline No & $7,647(53.1)$ & $4(2-7)$ & \\
\hline \multicolumn{4}{|l|}{ Income level $^{+}$} \\
\hline Low & $7,772(47.6)$ & $2(0-3)$ & $<0.01$ \\
\hline Middle & $3,539(21.7)$ & $3(2-5)$ & \\
\hline High & $5,003(30.7)$ & $5(3-8)$ & \\
\hline \multicolumn{4}{|l|}{ Access to media* } \\
\hline Yes & $9,934(60.9)$ & $2(0-4)$ & $<0.01$ \\
\hline No & $6,380(39.1)$ & $4(2-6)$ & \\
\hline \multicolumn{4}{|l|}{ AIDS awareness* } \\
\hline Yes & $5,497(33.7)$ & $5(3-8)$ & $<0.01$ \\
\hline No & $10,817(66.3)$ & $2(1-4)$ & \\
\hline \multicolumn{4}{|c|}{ Experience of a child's death* } \\
\hline Yes & $3,591(2.0)$ & $2(1-5)$ & $<0.01$ \\
\hline No & $12,723(78)$ & $3(1-6)$ & \\
\hline \multicolumn{4}{|c|}{ Desire for pregnancy* } \\
\hline Yes & $14,345(87.9)$ & $3(1-5)$ & $<0.01$ \\
\hline No & $1,969(12.1)$ & $3(1-5)$ & \\
\hline \multicolumn{4}{|l|}{ Parity* } \\
\hline Primipara & $3,583(22)$ & $4(2-7)$ & $<0.01$ \\
\hline Multipara & $12,731(78)$ & $3(1-5)$ & \\
\hline \multicolumn{4}{|l|}{ Birth order* } \\
\hline$\leq 4$ & $12,185(74.7)$ & $3(2-6)$ & $<0.01$ \\
\hline$>4$ & $4,129(25.3)$ & $2(0-4)$ & \\
\hline
\end{tabular}

*Mann-Whitney test.

${ }^{\dagger}$ Kruskal-Wallis test.

in the data. Both NBH and ZINB models show nearly similar performance, and hence, any of these models can be used as a final model. Hence, the ZINB model is further fitted as a final model for factor selection for the present data.

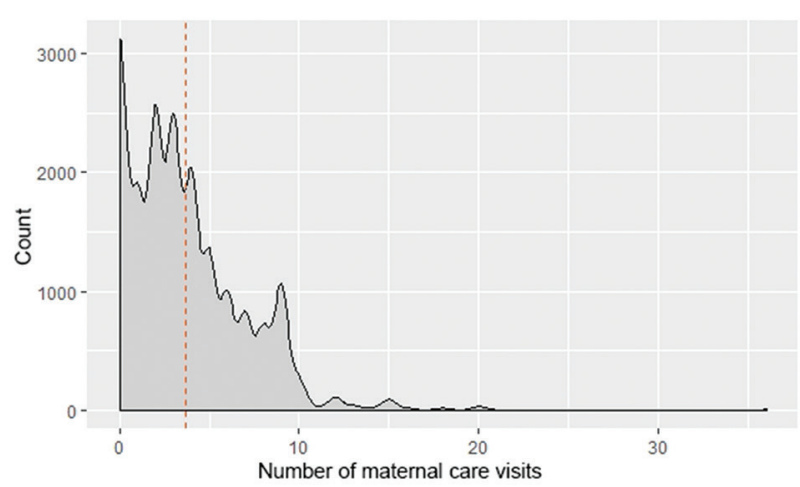

Figure 1. Frequency distribution of maternal care visits in Pakistan.

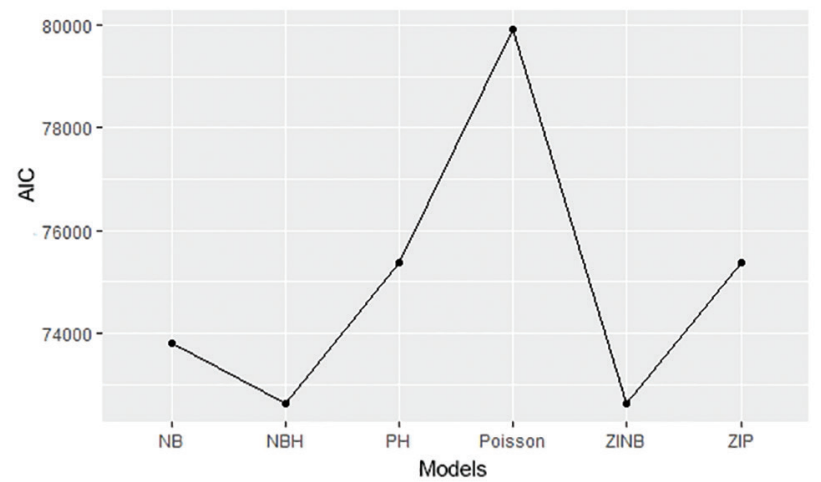

Figure 2. The modeling accuracy of count regression models over the data of maternal health care services utilization.

\section{Zero-inflated negative binomial regression}

Table 2 represents the estimates of odds for the ZI (logistic) regression component and count (NB) regression component of the ZINB regression model. The ZI component refers to the logistic model which predicts the probability of use versus non-use of maternal care services. The ZI regression component shows that the education level of women, the income level of family, access to media, AIDS awareness, desire for pregnancy, parity, and birth order are significant factors of maternal health care services utilization.

Furthermore, the results of the ZI component show that unwanted pregnancy increases the odds of not utilizing maternal care services by $24 \%$. It is found that middle and highincome levels decrease the odds of non-use of maternal care services by $47 \%$ and $69 \%$, respectively.

The count regression component refers to the NB model employed for positive counts. The count component shows that age, education level of women, area, domestic violence, the income level of family, access to media, AIDS awareness, an experience of a child's death, parity, and birth order are 
Table 2. Parameter estimates and $95 \%$ confidence interval (Cl) estimates for ZINB model on maternal care utilization

\begin{tabular}{|c|c|c|}
\hline Coefficients & $\begin{array}{l}\text { Zero-inflated } \\
\text { regression }\end{array}$ & $\begin{array}{l}\text { Count } \\
\text { regression }\end{array}$ \\
\hline Intercept & $0.12(0.07-0.18)$ & $3.85(3.59-4.13)$ \\
\hline $\begin{array}{l}\text { Province (Punjab) } \\
\text { Sindh }\end{array}$ & $\begin{array}{c}\text { Ref } \\
0.95(0.83-1.09)\end{array}$ & $\begin{array}{c}\text { Ref } \\
1.02(0.99-1.05)\end{array}$ \\
\hline $\begin{array}{l}\text { Age }(\leq 20 \text { years }) \\
>20 \text { years }\end{array}$ & $\begin{array}{c}\text { Ref } \\
1.13(0.87-1.48)\end{array}$ & $\begin{array}{c}\text { Ref } \\
1.13(1.08-1.18)^{*}\end{array}$ \\
\hline $\begin{array}{l}\text { Education level (Illiterate) } \\
\text { Literate }\end{array}$ & $\begin{array}{c}\text { Ref } \\
0.43(0.35-0.54)^{*}\end{array}$ & $\begin{array}{c}\text { Ref } \\
1.15(1.12-1.19)^{*}\end{array}$ \\
\hline $\begin{array}{l}\text { Area (Urban) } \\
\text { Rural }\end{array}$ & $\begin{array}{c}\text { Ref } \\
0.89(0.75-1.06)\end{array}$ & $\begin{array}{c}\text { Ref } \\
0.94(0.92-0.97)^{*}\end{array}$ \\
\hline $\begin{array}{l}\text { Domestic Violence (No) } \\
\text { Yes }\end{array}$ & $\begin{array}{c}\text { Ref } \\
1.06(0.92-1.22)\end{array}$ & $\begin{array}{c}\text { Ref } \\
0.91(0.89-0.93)^{*}\end{array}$ \\
\hline $\begin{array}{l}\text { Income level (Low) } \\
\text { Middle } \\
\text { High }\end{array}$ & $\begin{array}{c}\text { Ref } \\
0.53(0.43-0.65)^{*} \\
0.31(0.23-0.42)^{*}\end{array}$ & $\begin{array}{c}\text { Ref } \\
1.25(1.20-1.29)^{*} \\
1.56(1.50-1.62)^{*}\end{array}$ \\
\hline $\begin{array}{l}\text { Access to media (No) } \\
\text { Yes }\end{array}$ & $\begin{array}{c}\text { Ref } \\
0.52(0.45-0.60)^{*}\end{array}$ & $\begin{array}{c}\text { Ref } \\
1.07(1.04-1.10)^{*}\end{array}$ \\
\hline $\begin{array}{l}\text { AIDS Awareness (Yes) } \\
\text { No }\end{array}$ & $\begin{array}{c}\text { Ref } \\
1.75(1.36-2.24)^{*}\end{array}$ & $\begin{array}{c}\text { Ref } \\
0.86(0.83-0.88)^{*}\end{array}$ \\
\hline $\begin{array}{l}\text { Experience of a child's } \\
\text { death (Yes) } \\
\text { No }\end{array}$ & $\begin{array}{c}\text { Ref } \\
1.13(0.97-1.32)\end{array}$ & $\begin{array}{c}\text { Ref } \\
0.90(0.87-0.93)^{*}\end{array}$ \\
\hline $\begin{array}{l}\text { Desire for pregnancy (Yes) } \\
\text { No }\end{array}$ & $\begin{array}{c}\text { Ref } \\
1.24(1.03-1.49)^{*}\end{array}$ & $\begin{array}{c}\text { Ref } \\
1.03(0.99-1.07)\end{array}$ \\
\hline $\begin{array}{l}\text { Parity (Primipara) } \\
\text { Multipara }\end{array}$ & $\begin{array}{c}\text { Ref } \\
1.59(1.28-1.99)^{*}\end{array}$ & $\begin{array}{c}\text { Ref } \\
0.85(0.83-0.88)^{*}\end{array}$ \\
\hline $\begin{array}{l}\text { Birth order }(\leq 4) \\
>4\end{array}$ & $\begin{array}{c}\text { Ref } \\
1.41(1.21-1.64)^{*}\end{array}$ & $\begin{array}{c}\text { Ref } \\
0.90(0.87-0.93)^{*}\end{array}$ \\
\hline
\end{tabular}

$* P<0.05$

significant factors of maternal health care services utilization. Further analysis shows that the expected number of maternal care visits for women aged $\leq 20$ years is $13 \%$ higher than the average visits of women $>20$ years. Similarly, $15 \%$ higher average maternal care visits are observed for literate women.

\section{Discussion}

This article considers several count data models to examine factors associated with maternal health care visits using a dataset with overdispersion and inflated with zeros from UNICEF's MICS 2014 in Pakistan. Six count regression models are compared in terms of AIC. The model comparison identifies that ZINB and NBH models are better fitted for modeling the observed data with excess zeros and overdispersion but ZINB was the best choice due to easy interpretation and understandability.
Poisson and NB models are insufficient in the presence of excess zero counts. A past study has reported the performance of count models for health data concluding the ZINB model to be best fitted for overdispersed and zero-inflated response variables [11]. However, in the presence of overdispersionand excess of zeros, the NBH model is a better choice compared to other zero adjusted models [14].

Several studies have been conducted to examine the association of maternal care utilization with different factors. The present study shows that consistent with the general findings of earlier studies, the likelihood of maternal care utilization is influenced by the levels of maternal education and maternal age $[15,16]$. Rural area resident women show a reduced average number of visits for maternal care. Previous studies showed that women of rural areas had fewer maternal visits compared to women of urban areas. Women with advanced aged husbands show increased expected positive counts of antenatal care visits for the present analysis. A previous study showed that older husbands increased antenatal care utilization for their wives for rural and urban areas [17]. The current results show that domestic violence decreases the average of attending maternal care visits. Past research reported that abused women were less likely to have adequate prenatal care visits [18]. The expected number of antenatal care visits increases with increasing income levels. Past evidence supported that increase in income level of family raised the probability of antenatal care utilization [15, 19]. Affirming to past studies access of women toward media significantly increased the chances of greater use of antenatal care visits $[20,21]$. Consistent with previous research studies desirability of pregnancy is found significantly associated with antenatal care utilization $[15,17]$. Birth order ranking is found associated with the use and non-use as well as frequency of maternal care visits for the observed data. Previous studies explained the possible reason for this association including the cognition and confidence gained from previous birth experiences [22]. Multiparae women consumed less average of antenatal care visits for the observed data. Past research has been proven for Asia and Sub-Saharan Africa [15, 23]. Women who had not experienced the death of a child had reduced expected maternal care visits. Consistent with this result, previous terminated pregnancy or child death is associated with an increased number of maternal care visits [24].

\section{Conclusion}

This study attempts to compare models to handle count data with overdispersion and excess of zeros to efficiently determine the factors associated with maternal health care utilization. ZINB regression model is found best fitted for the 
observed zero-inflated count data. It presents a key advancement for the analysis of health care utilization data. It is recommended, based on study findings, that interventions to improve maternal care services utilization should address individuals and systems to reduce social and economic marginalization.

Author contributions. All the authors contributed substantially to the conception and design of this study. MA contributed substantially to the initial and final writeup of the manuscript. MS contributed substantially to the acquisition of data, analyzed, and interpreted the data. MS drafted the manuscript. TM contributed substantially to its critical revision. All the authors approved the final version submitted for publication and take responsibility for the statements made in the published article.

Acknowledgment. The authors would like to acknowledge UNICEF's Multiple Indicator Cluster Survey (MICS) who made their data available for free.

Conflict of interest statement. The authors have completed and submitted the International Committee of Medical Journal Editors Uniform Disclosure Form for Potential Conflicts of Interest. None of the authors disclose any conflict of interest.

\section{References}

[1] World Health Organization. Household-to hospital continuum of maternal and newborn care. [online] 2005 [cited 2016 Dec 5]. Available from: https://www.who.int/pmnch/media/publications/ aonsectionII.pdf

[2] Rosenfield A, Maine D, Freedman L. Meeting MDG-5: an impossible dream? Lancet. 2006; 368:1133-5.

[3] Assembly UN General. Universal declaration of human rights. New York: UN General Assembly; 1948.

[4] Starrs AM. Safe motherhood initiative: 20 years and counting. Lancet. 2006; 368:1130-2.

[5] Hogan MC, Foreman KJ, Naghavi M, Ahn SY, Wang M, Makela SM, et al. Maternal mortality for 181 countries, 1980-2008: a systematic analysis of progress towards Millennium Development Goal 5. Lancet. 2010; 375:1609-23.

[6] Mahmood A, Sultan M. National Institute of Population Studies (NIPS) (Pakistan), and Macro International Inc. Pakistan Demographic and Health Survey. 2006; 7:123-45.
[7] National Institute of Population Studies. Pakistan Demographic and Health Survey 2012-13 Islamabad. [online]. 2013 [cited 2016 Dec 5]. Available from: https://dhsprogram.com/pubs/pdf/FR290/FR290.pdf

[8] Agha S. Determinants of facility delivery in rural Jhang Pakistan [PhD thesis]. New Orleans: Department of International Health, Tulane University; 2010.

[9] Mullahy J. Specification and testing of some modified count data models. J Econ. 1986; 33:341-65.

[10] Consul PC, Famoye F. Generalized Poisson regression model. Comm Stat Theory Methods. 1992; 21:89-109.

[11] Hu MC, Pavlicova M, Nunes EV. Zero-inflated and hurdle models of count data with extra zeros: examples from an HIV-risk reduction intervention trial. Am J Drug Alcohol Abuse. 2011; 37:367-75.

[12] Joe H, Zhu R. Generalized Poisson distribution: the property of mixture of Poisson and comparison with negative binomial distribution. Biom J. 2005; 47:219-29.

[13] Flynn M, Francis LA. More flexible glms zero-inflated models and hybrid models. Casualty Actuarial Soc. 2009; 2009:148-224.

[14] Gurmu S, Trivedi PK. Excess zeros in count models for recreational trips. J Bus Econ Stat. 1996; 14:469-77.

[15] Guliani H, Sepehri A, Serieux J. Determinants of prenatal care use: evidence from 32 low-income countries across Asia, Sub-Saharan Africa and Latin America. Health Pol Plan. 2013;czt045.

[16] Sepehri A, Sarma S, Simpson W, Moshiri S. How important are individual, household and commune characteristics in explaining utilization of maternal health services in Vietnam? Soc Sci Med. 2008; 67:1009-17.

[17] Alexandre PK, Saint-Jean G, Crandall L, Fevrin E. Prenatal care utilization in rural areas and urban areas of Haiti. Pan Am J Pub Health. 2005; 18:84-92.

[18] Cha S, Masho SW. Intimate partner violence and utilization of prenatal care in the United States. J Interpers Violence. 2014; 29:911-27.

[19] Gage AJ. Barriers to the utilization of maternal health care in rural Mali. Soc Sci Med. 2007; 65:1666-82.

[20] Bbaale E. Factors influencing timing and frequency of antenatal care in Uganda. Aus Med J. 2011; 4:431.

[21] Tarekegn SM, Lieberman LS, Giedraitis V. Determinants of maternal health service utilization in Ethiopia: analysis of the 2011 Ethiopian demographic and health survey. BMC Pregnancy Childbirth. 2014; 14:1.

[22] Jejeebhoy SJ, Sathar ZA. Women's autonomy in India and Pakistan: the influence of religion and region. Popul Dev Rev. 2001; 27:687-712.

[23] Short SE, Zhang F. Use of maternal health services in rural China. Popul Stud. 2004; 58:3-19.

[24] Zaky HHM, Armanious D M, Hussein MA. Impact of the changes in women's characteristics over time on antenatal health care utilization in Egypt (2000-2008). Open J Obstet Gynecol. 2015; 5:542. 